

\section{Intracranial Calcifications in Childhood}

Isolated x Non Isolated ICC

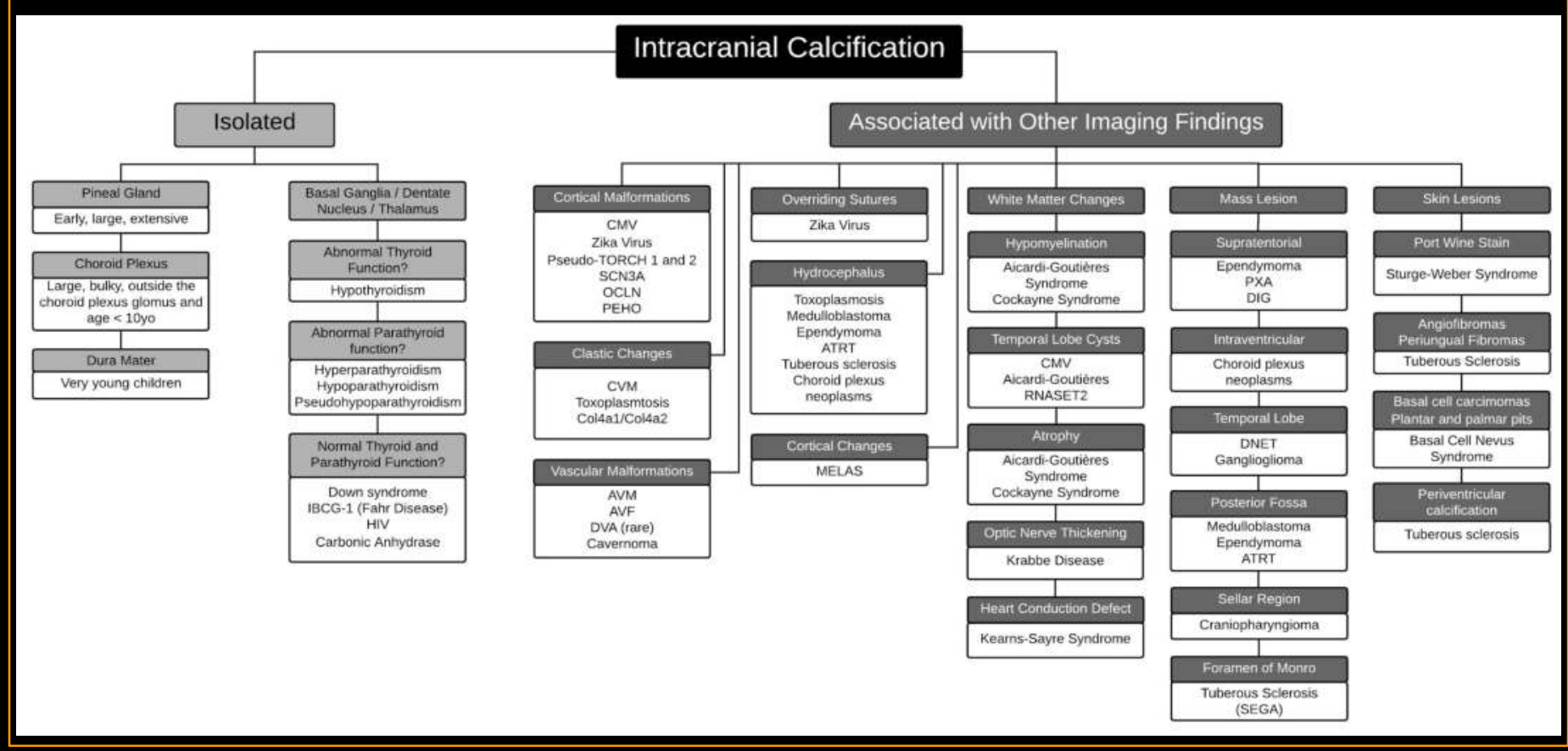

Infectious ICC

CMV
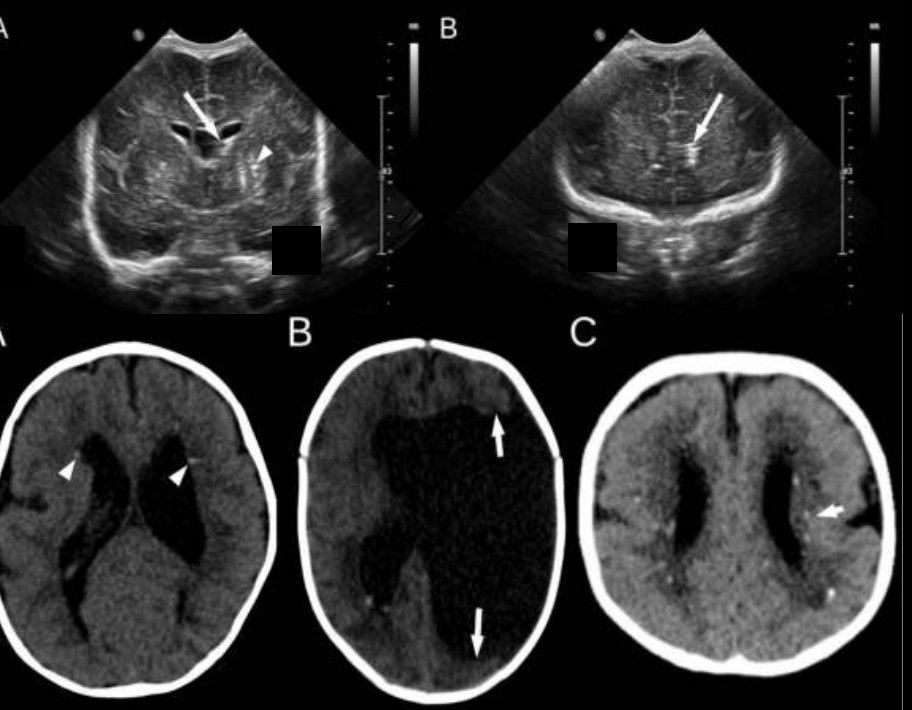

(19)

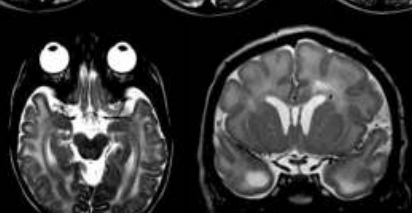

- ICC $\rightarrow$ most common

neuroimaging finding $(34 \%-70 \%$ of the cases)

\section{- ICC is variable}

- Thick and chunky

- Fine and punctate

- Periventricular or subependymal

- Basal ganglia

- Subcortical white matter

- Cerebellum

Additional imaging findings:

- Anterior temporal lobe cysts

- Ventriculomegaly

- WM signal changes

- Microcephaly

- Polymicrogyria

- Lissencephaly

- Porencephaly

- Schizencephaly

- Chorioretinitis
Infectious ICC

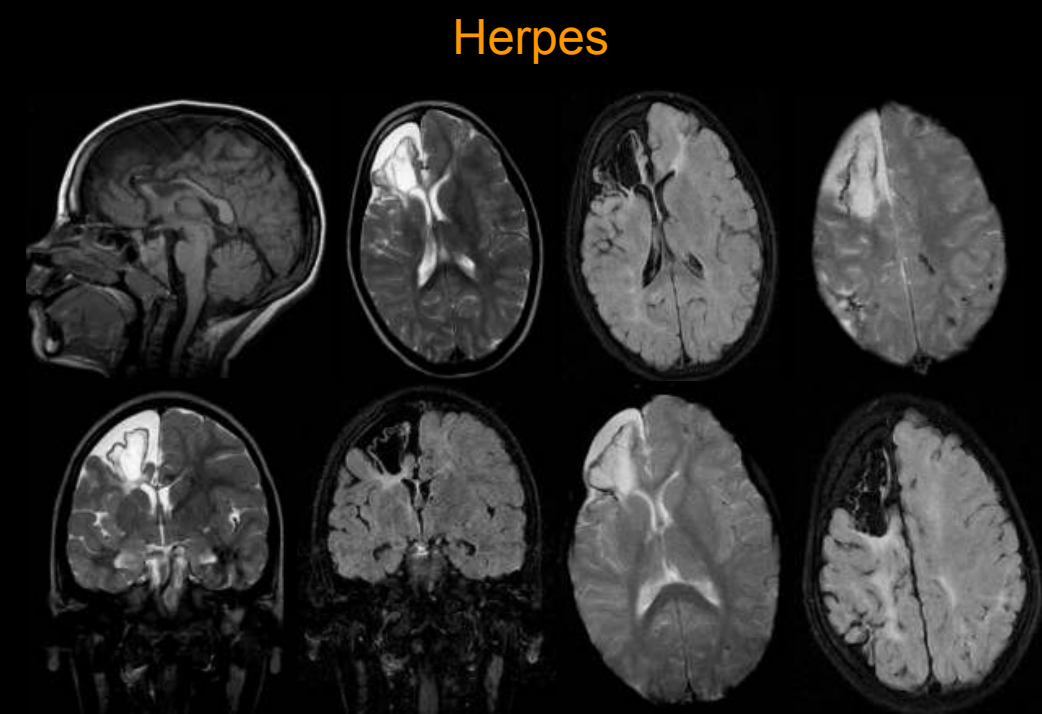

- Intrauterine - (rare, $5 \%$ of the cases)

- Perinatal/Postnatal - (materna genital tract, $85 \%$ of the cases)

- Neonatal HSV - in the first 3 weeks after birth.

Encephalitis, seizures, lethargy, irritability, tremors, poor feeding and temperature liability.

- Intrauterine HSV -

Encephalomalacia, ventricular enlargement, scattered calcifications and microcephaly
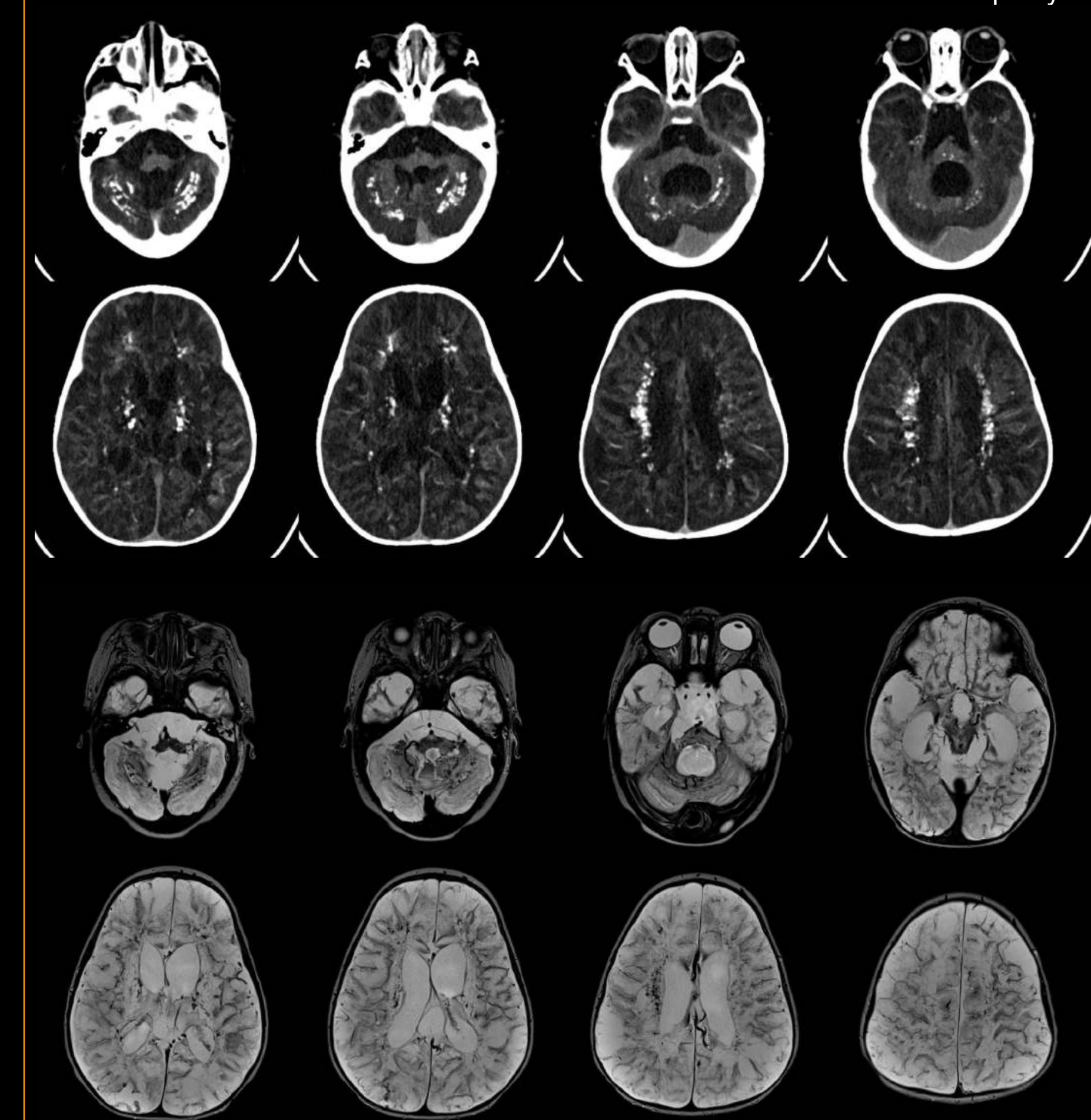

- Overlapping sutures

- Cerebral volume loss

- Malformations of cortical development

(cobblestone, polymicrogyria, pachygyria)

- CC abnormalities (agenesis, dysgenesis)

- Ventriculomegaly; cerebellar abnormalities (i.e; hemisphere hypoplasia or maldevelopment, vermis hypoplasia); brainstem hypoplasia/atrophy; delayed myelination

Infectious ICC HIV

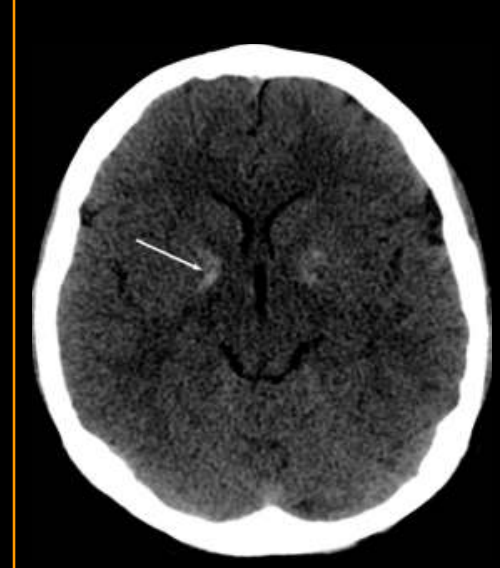

- Incidence of perinatal HIV is dramatically decreasing worldwide

\section{- Cerebral atrophy}

- Myelin loss (diffuse or multifocal)

- ICC

- Mineralizing microangiopathy involving primarily the BG and subcortical WM with frontal lobe predilection

\section{- BG calcification is usually faint}

- Later in the disease course, patients may develop vasculopathy with vascular ectasia and fusiform aneurysms

- As a consequence of acquired immunodeficiency syndrome progressive multifocal leukoencephalopathy, CMV and varicella-zoster related encephalitis, CNS lymphoma and secondary CNS tumors may ensue

\section{Infectious ICC}

Herpes

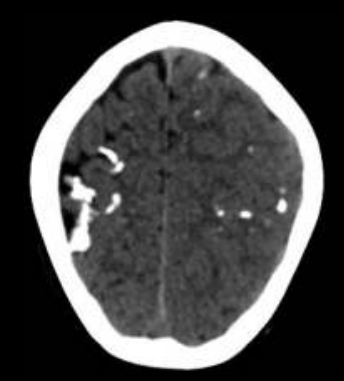

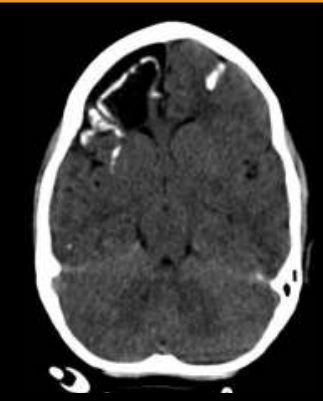

- Perinatal/postnatal HSV - Variable imaging appearance, normal, edema and multifocal diffusion restriction with or without associated hemorrhage, severe parenchymal destruction, diffuse cystic, encephalomalacia, cortical thinning, atrophy, scattered calcifications, and ventricular enlargement

- Neonatal HSV - No predilection for the temporal lobe and insular cortex, with multifocal appearance, involving the white matter, cortical gray matter, basal ganglia, temporal lobes, watershed areas and occasionally the brainstem and cerebellum

If serology is negative for TORCH (or other) congenital infection, several other diagnoses have imaging findings that mimic congenital CNS infection. Some of these diagnoses to consider include pseudo-TORCH syndrome (i.e. OCLN gene mutation), Cockayne syndrome, metabolic disorders (such as biotinidase deficiency and carbonic anhydrase II deficiency) and Aicardi-Goutieres syndrome.

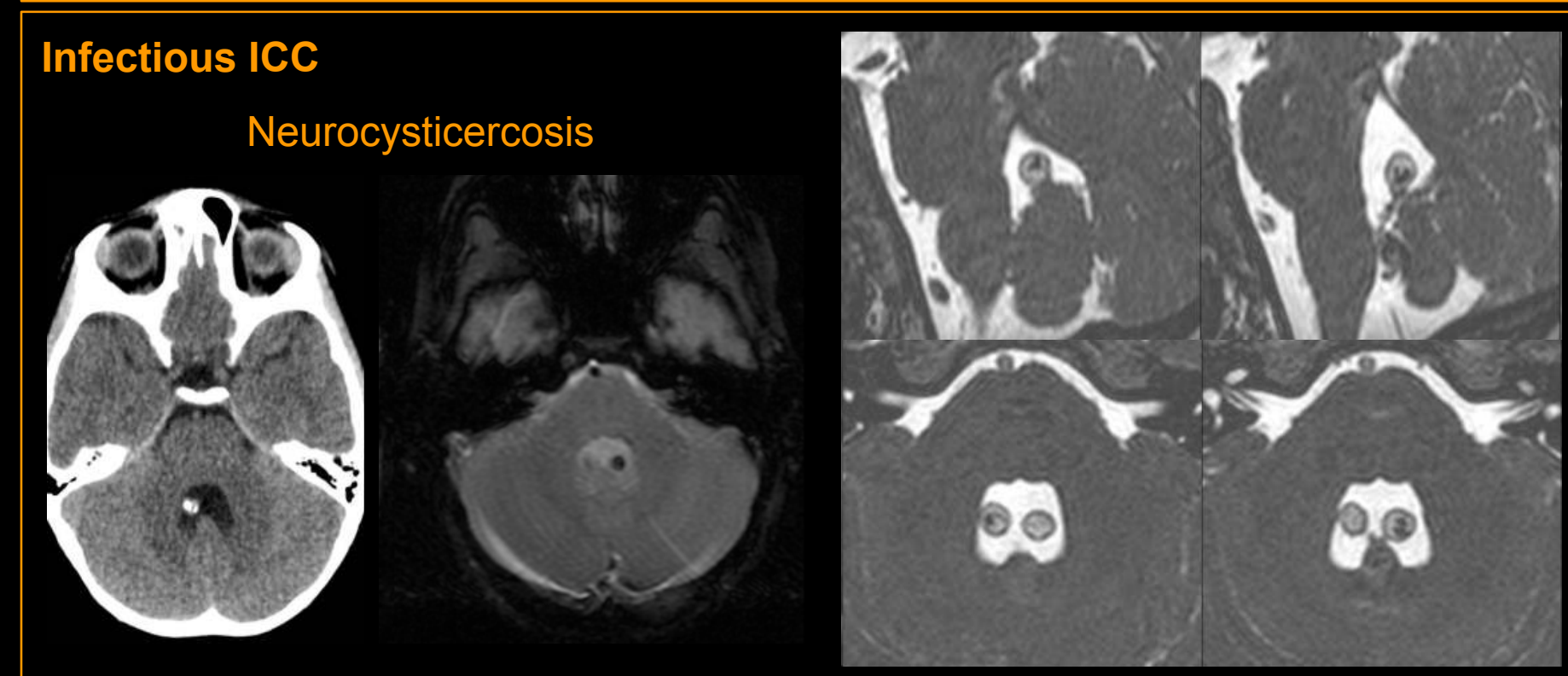

Toxic ICC

Misoprostol - Cytotec

- Synthetic prostaglandin E1 analog Gastroduodenal injury following NSAID
- Off-label: abortion/labor induction, management of miscarriage, uterine cervix ripening preparation before surgical procedures, and postpartum hemorrhage 


\section{Intracranial Calcifications in Childhood}

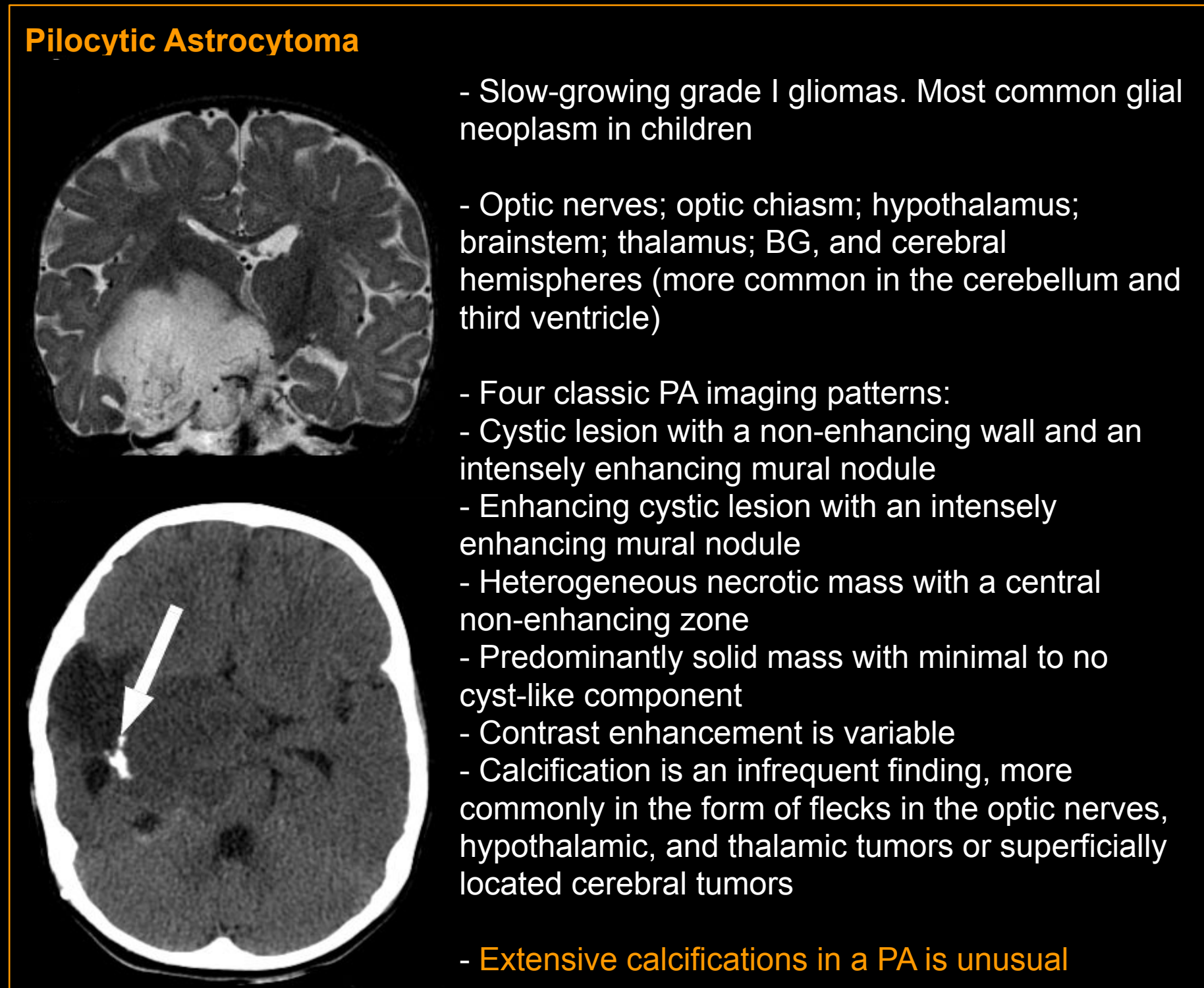

Ganglioglioma
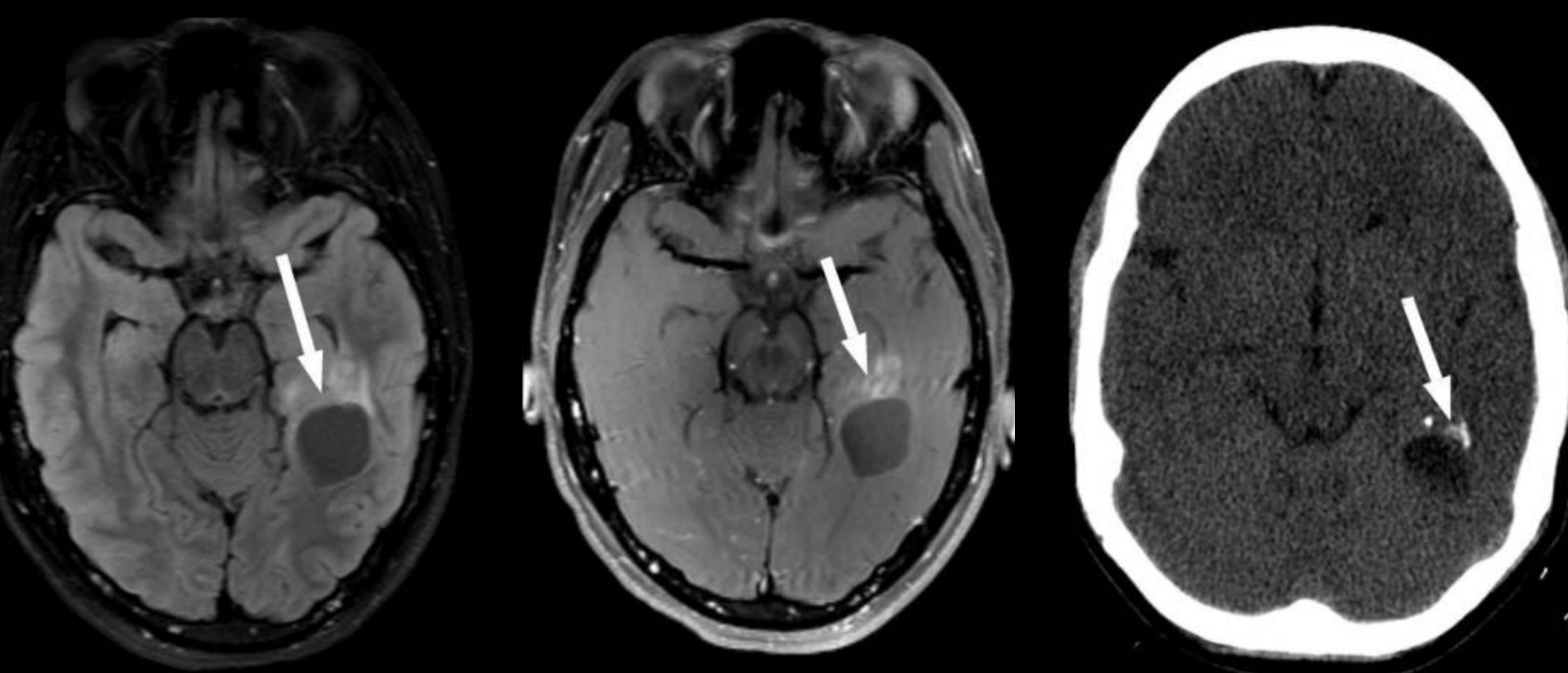

- Mixed neuroepithelial tumors with neoplastic ganglion and glial components

- Cortically based, most commonly in the temporal lobes

- Most common neoplastic cause of refractory epilepsy in children and young adults

- Typically partially cystic, with a mural enhancing nodule in $40 \%$ of cases; calcifications in $30 \%$; adjacent inner table scalloping

- Surrounding edema is uncommon and should prompt a different diagnosis possibility or raise the suspicion of anaplastic changes

- Calcification is a common finding (28-41\%) which are commonly large, not associated with mass effect or evidence of surrounding vasogenic edema

Dysembryoplastic Neuroepithelial Tumor
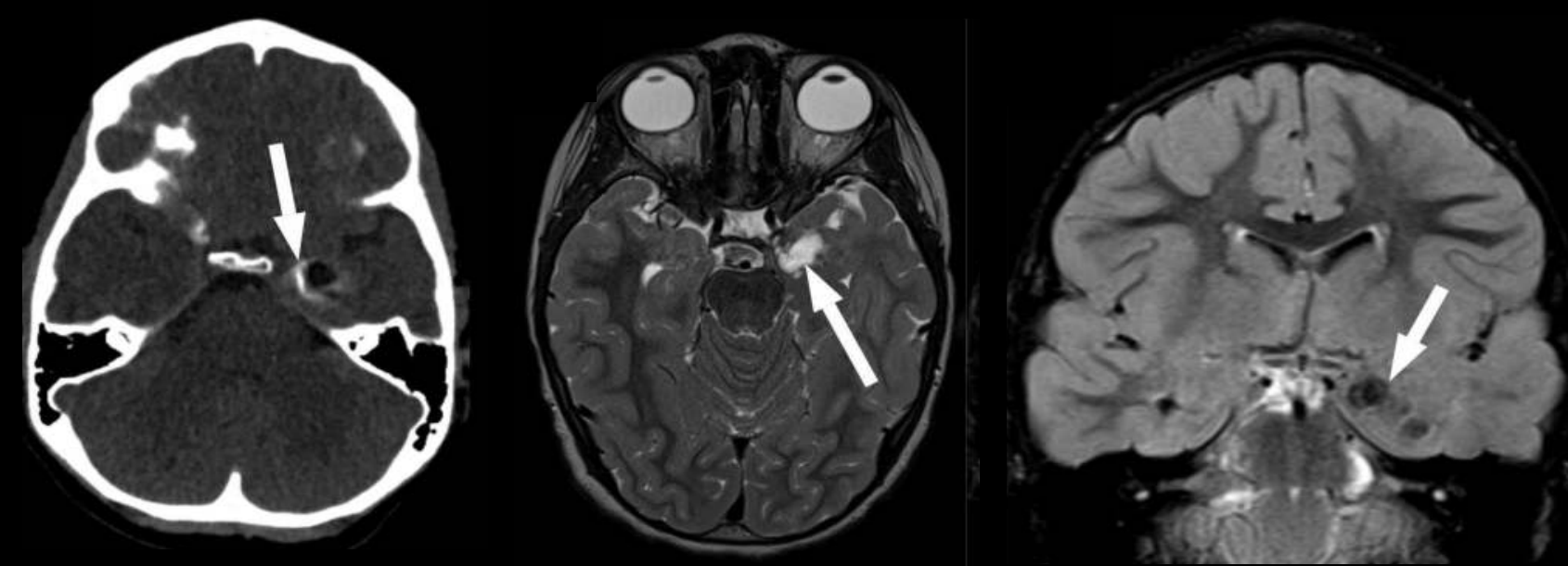

- Benign glioneuronal neoplasms typically associated with intractable seizures in children and young adults

- More commonly supratentorial; predominantly cortical and intra-axial tumors; characterized by a multinodular architecture

- Well defined peripheral masses, with a cyst-like appearance, lacking mass effect or perilesional edema, that may remodel the adjacent inner table of the skull

- They may present FLAIR hyperintense ring sign, described as a well-defined FLAIR hyperintense margin separating the tumor from the surrounding normal brain parenchyma

- Cystic changes may occur in $24 \%$ of the cases and focal enhancement in $20 \%$

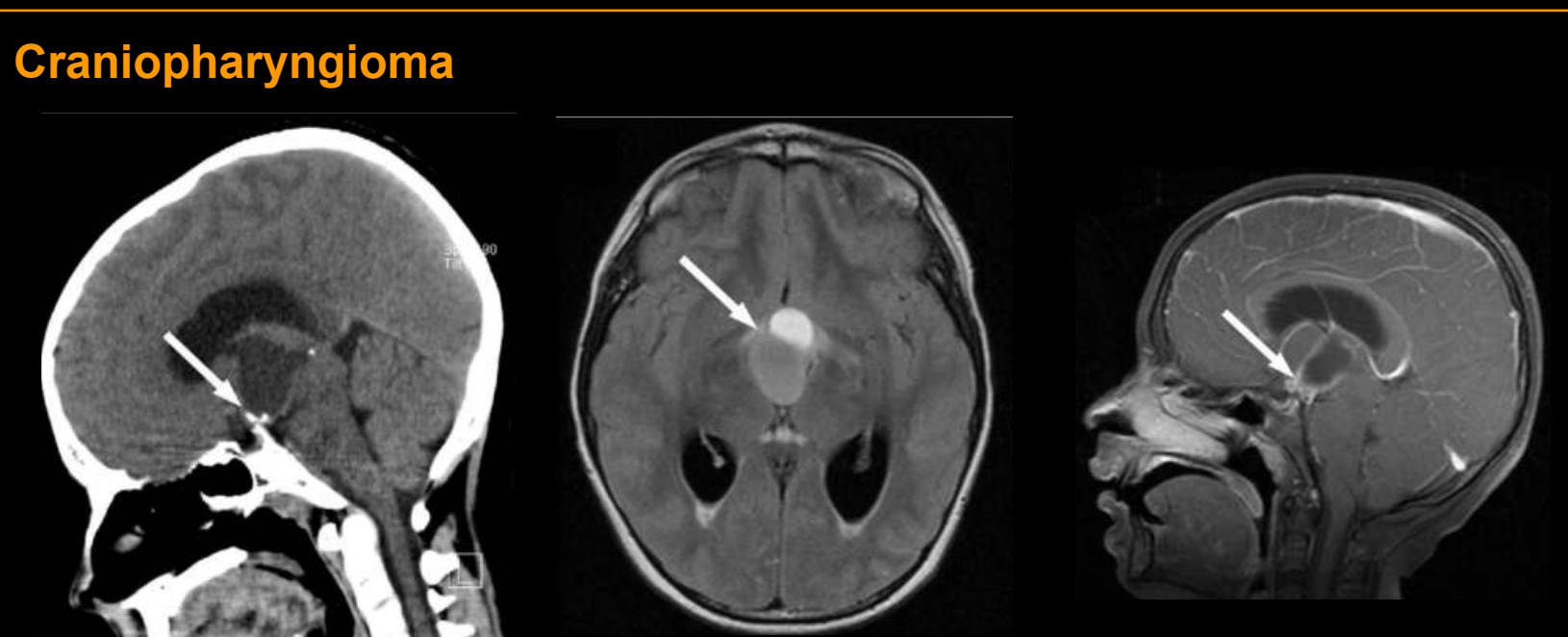

- Common suprasellar / intrasellar mass from remnants of the craniopharyngeal duct (Rathke's pouch)

- Bimodal age distribution 5 to 14 , and 50 to 74 years

- Histologically benign but clinically aggressive

- Contrast enhancement, T1 hyperintense signal, cystic changes, and calcification

- Increased T1 (high protein content, cholesterol, mild calcification, or hemorrhage)

- Calcification is a prevalent imaging finding in craniopharyngiomas with varying incidences more common in children $(90 \%)$ than in adults $(70 \%)$

- Calcification is more common in the adamantinomatous type than in the papillary type

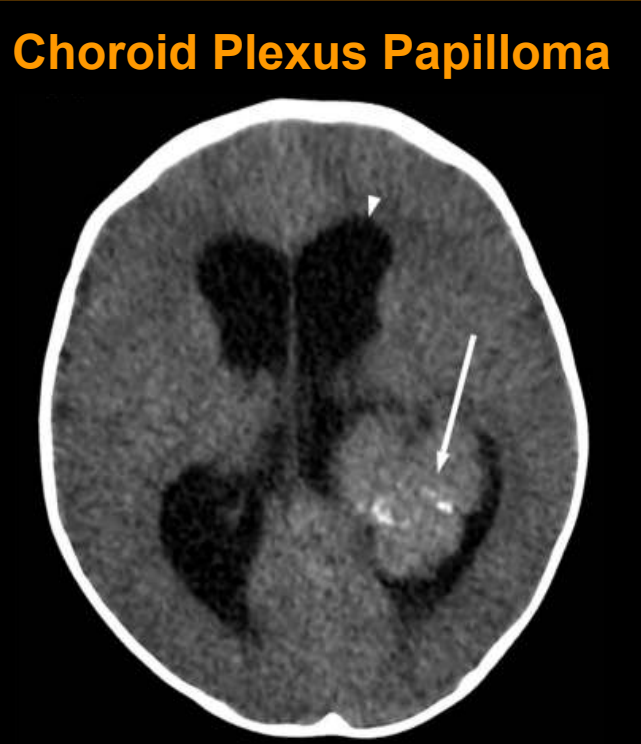

- Pediatric CPPs are typically in the lateral ventricles

- Increased intracranial pressure due to increased CSF secretion such as headache, gait disturbances, papilledema, bulging fontanelle, macrocephaly, and abducens nerve palsy

- Lobulated (cauliflower-like appearance),

well-defined, hyperdense masses with avid contrast enhancement

- MRI demonstrates T1 iso- to hypointense signal, and T2 hyperintense signal, with intense contrast enhancement

- Due to increased vascularity within the tumors, CPPs may show small flow-voids

\section{- In $25 \%$ of the cases, these lesions demonstrate fine, speckled calcification}

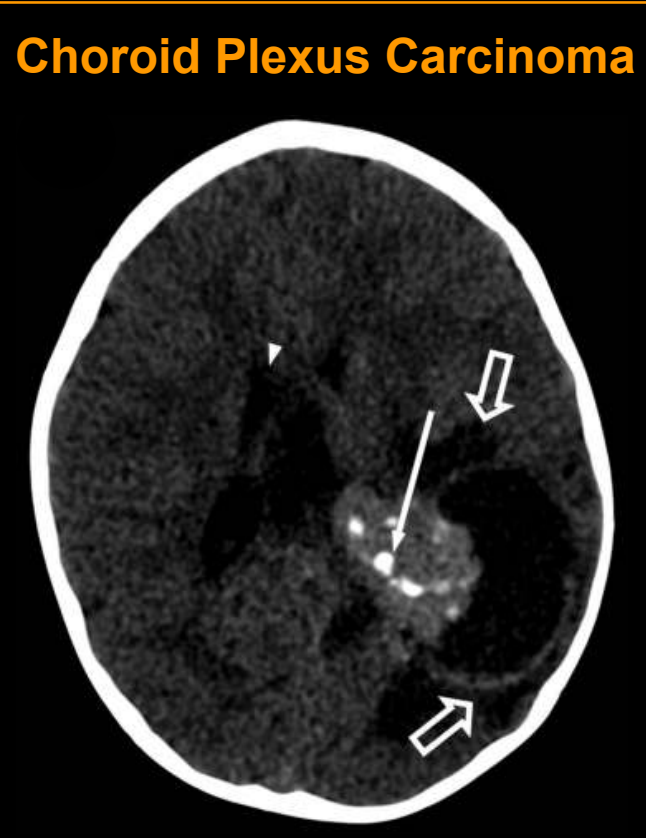

- Pediatric CPCs are also typically located in the lateral ventricles

- Malignant tumors (grade III tumors), more commonly in young children ( $80 \%$ of the cases)

- CPCs enhancement is more heterogeneous due to necrosis, cysts, hemorrhage, and brain invasion

- Patients with CPCs may present hydrocephalus, less common than in cases of CPPs

- Calcification may be seen in $20-25 \%$ of cases

- At presentation, CPCs may show CSF seeding; therefore, neuroimaging of the entire neural axis is recommended before surgery

Subependymal Giant Cell Astrocytoma (SEGA)

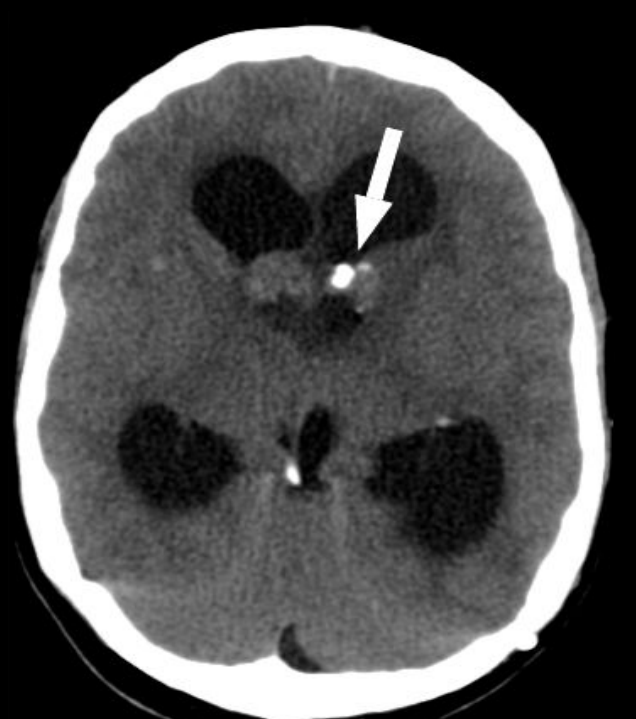

- Most common cerebral neoplasm in patients with tuberous sclerosis complex (TSC)

- Occur in the 1st and 2nd decades

$10 \%-15 \%$ of all patients with tuberous sclerosis

- SEGAs are typically intraventricular lesions, near the foramen of Monro and can be unilateral or bilateral

- Slow-growing glioneuronal tumors with a benign biologic behavior (grade I neoplasm)

- SEGAs probably arise from subependymal nodules (hamartomas) in the ventricular wall of patients with tuberous sclerosis 


\section{Intracranial Calcifications in Childhood}

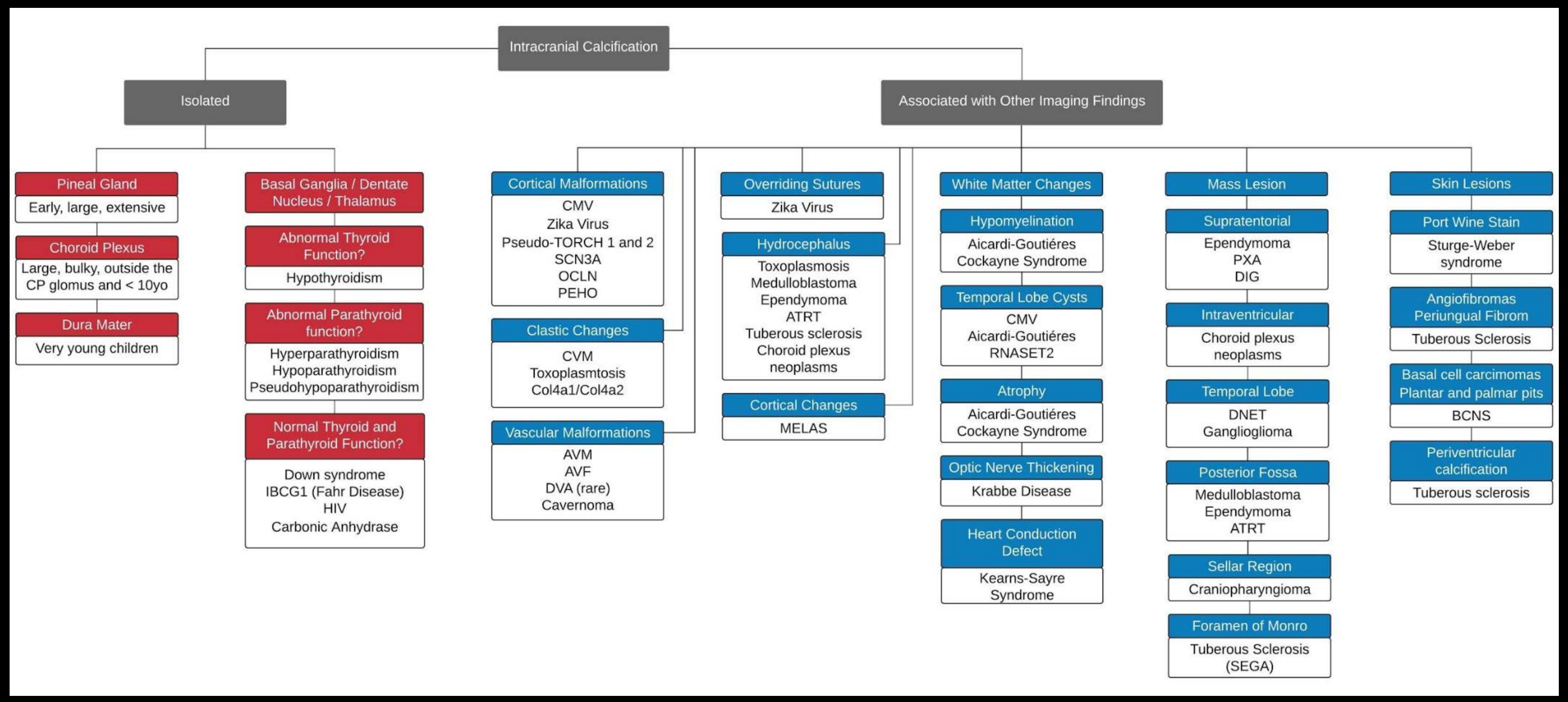

1. Livingston JH, Stivaros S, Warren D, Crow YJ (2014) Intracranial calcification in childhood: a review of aetiologies and recognizable phenotypes. Dev Med Child Neurol 56:612-626. doi: $10.1111 /$ dmen. 12359

2. Smith RS, Kenny CJ, Ganesh V, et al. (2018) Sodium channel SCN3A (nav1.3) regulation of human cerebral cortical folding and oral motor development. Neuron 99:905-913.e7. doi:

10.1016/j.neuron.2018.07.052

3. Roizen J, Levine MA (2012) Primary hyperparathyroidism in children and adolescents. J Chin Med Assoc 75:425-434. doi: 10.1016/j.jcma.2012.06.012

4. de la Plaza Llamas R, Ramia Ángel JM, Arteaga Peralta V, et al. (2016) Brain calcifications and primary hyperparathyroidism. Cirugía Española (English Edition) 94:e5-e7. doi:

10.1016/j.cireng.2015.12.001

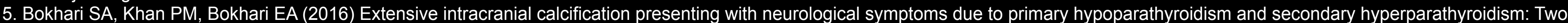

case .... Journal of Health Specialties

6. Markowitz ME, Underland L, Gensure R (2016) Parathyroid Disorders. Pediatr Rev 37:524-535. doi: 10.1542/pir.2015-0076

7. Fulop M, Zeifer B (1991) Case report: extensive brain calcification in hypoparathyroidism. Am J Med Sci 302:292-295. doi: 10.1097/00000441-199111000-00006

8. Haft AS (1953) Idiopathic hypoparathyroidism and cataract; report of four cases. AMA Arch Ophthalmol 50:455-461. doi: 10.1001/archopht.1953.00920030463005

9. Mendelsohn DB, Hertzanu Y (1984) Hypoparathyroidism with cerebral calcification extending beyond the extrapyramidal system. A case report. South African medica ..

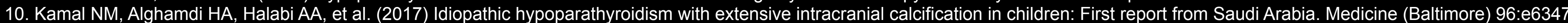

doi: 10.1097/MD.0000000000006347

11. Mantovani G (2011) Clinical review: Pseudohypoparathyroidism: diagnosis and treatment. J Clin Endocrinol Metab 96:3020-3030. doi: 10.1210/jc.2011-1048

12. Visconti P, Posar A, Scaduto MC, et al. (2016) Neuropsychiatric phenotype in a child with pseudohypoparathyroidism. J Pediatr Neurosci 11:267-270. doi: 10.4103/1817-1745.193373

13. Bosley TM, Salih MA, Alorainy IA, et al. (2011) The neurology of carbonic anhydrase type II deficiency syndrome. Brain 134:3502-3515. doi: 10.1093/brain/awr302

14. Hanley P, Lord K, Bauer AJ (2016) Thyroid disorders in children and adolescents: A review. JAMA Pediatr 170:1008-1019. doi: 10.1001/jamapediatrics.2016.0486

15. Dinizio A, Vincent J, Nickerson J (2016) Intracranial calcifications in the pediatric age group: an imaging review. J Pediatr Neuroradiol 04:049-059. doi: 10.1055/s-0036-1583312

16. El-Hattab AW, Adesina AM, Jones J, Scaglia F (2015) MELAS syndrome: Clinical manifestations, pathogenesis, and treatment options. Mol Genet Metab 116:4-12. doi:

10.1016/j.ymgme.2015.06.004

17. Malhotra K, Liebeskind DS (2016) Imaging of MELAS. Curr Pain Headache Rep 20:54. doi: 10.1007/s11916-016-0583-7

18. Kearns TP (1958) Retinitis pigmentosa, external ophthalmoplegia, and complete heart block. AMA Arch Ophthalmol 60:280. doi: 10.1001/archopht.1958.00940080296016

19. Saneto RP, Friedman SD, Shaw DWW (2008) Neuroimaging of mitochondrial disease. Mitochondrion 8:396-413. doi: 10.1016/j.mito.2008.05.003

20. Scheibye-Knudsen M, Croteau DL, Bohr VA (2013) Mitochondrial deficiency in Cockayne syndrome. Mech Ageing Dev 134:275-283. doi: 10.1016/j.mad.2013.02.007

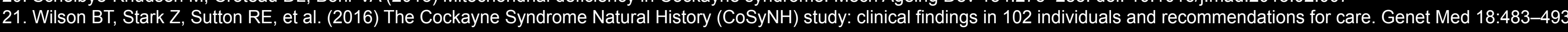

doi: 10.1038/gim.2015.110

22. Sonmez FM, Celep F, Ugur SA, Tolun A (2006) Severe form of Cockayne syndrome with varying clinical presentation and no photosensitivity in a family. J Child Neurol 21:333-337. doi:

10.1177/08830738060210041601

23. Koob M, Laugel V, Durand M, et al. (2010) Neuroimaging in Cockayne syndrome. AJNR Am J Neuroradiol 31:1623-1630. doi: 10.3174/ajnr.A2135

24. Patnaik A, Mishra SS, Das S (2017) Extensive intracranial calcification of pseudo-TORCH syndrome with features of Dandy-Walker malformation. Asian J Neurosurg 12:541-543. do:

10.4103/1793-5482.145162

25. Knoblauch H, Tennstedt C, Brueck W, et al. (2003) Two brothers with findings resembling congenital intrauterine infection-like syndrome (pseudo-TORCH syndrome). Am J Med Genet A

120A:261-265. doi: 10.1002/ajmg.a.20138

26. Cohen MC, Karaman I, Squier W, et al. (2012) Recurrent pseudo-TORCH appearances of the brain presenting as "Dandy-Walker" malformation. Pediatr Dev Pathol 15:45-49. doi:

10.2350/10-01-0783-CR.1

27. O'Driscoll MC, Daly SB, Urquhart JE, et al. (2010) Recessive mutations in the gene encoding the tight junction protein occludin cause band-like calcification with simplified gyration and polymicrogyria. Am J Hum Genet 87:354-364. doi: 10.1016/j.ajhg.2010.07.012

28. Mochida GH, Ganesh VS, Felie JM, et al. (2010) A homozygous mutation in the tight-junction protein JAM3 causes hemorrhagic destruction of the brain, subependymal calcification, and congenital cataracts. Am J Hum Genet 87:882-889. doi: 10.1016/j.ajhg.2010.10.026

29. Meuwissen MEC, Schot R, Buta S, et al. (2016) Human USP18 deficiency underlies type 1 interferonopathy leading to severe pseudo-TORCH syndrome. J Exp Med 213:1163-1174. doi

$10.1084 / j e m .20151529$

30. Ali M, Highet LJ, Lacombe D, et al. (2006) A second locus for Aicardi-Goutieres syndrome at chromosome 13q14-21. J Med Genet 43:444-450. doi: 10.1136/jmg.2005.031880

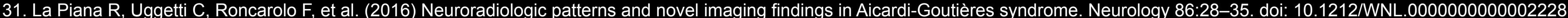

32. Uggetti C, La Piana R, Orcesi S, et al. (2009) Aicardi-Goutieres syndrome: neuroradiologic findings and follow-up. AJNR Am J Neuroradiol 30:1971-1976. doi: 10.3174/ajnr.A1694

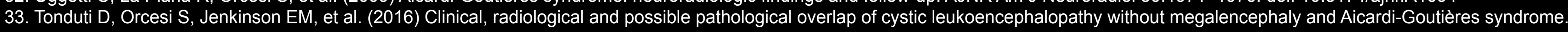

Eur J Paediatr Neurol 20:604-610. doi: 10.1016/j.ejpn.2016.03.009

34. Graziano ACE, Cardile V (2015) History, genetic, and recent advances on Krabbe disease. Gene 555:2-13. doi: 10.1016/j.gene.2014.09.046

35. Farina L, Bizzi A, Finocchiaro G, et al. (2000) MR imaging and proton MR spectroscopy in adult Krabbe disease. AJNR Am J Neuroradiol 21:1478-1482.

36. Percy AK, Odrezin GT, Knowles PD, et al. (1994) Globoid cell leukodystrophy: comparison of neuropathology with magnetic resonance imaging. Acta Neuropathol 88:26-32. doi:

$10.1007 / b f 00294356$

37. Wang H, Shao B, Wang L, Ye Q (2015) Fahr's disease in two siblings in a family: A case report. Exp Ther Med 9:1931-1933. doi: 10.3892/etm.2015.2356

38. Wu Y (2012) Fahr's Disease: Pediatric Presentation of a Rare Neurodegenerative Disorder (P01.236). Neurology 78:P01.236-P01.236.

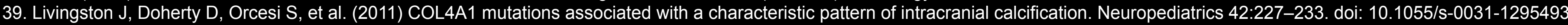

40. Verbeek E, Meuwissen MEC, Verheijen FW, et al. (2012) COL4A2 mutation associated with familial porencephaly and small-vessel disease. Eur J Hum Genet 20:844-851. doi:

10.1038/ejhg.2012.20

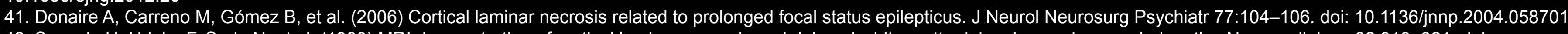

42. Sawada H, Udaka F, Seriu N, et al. (1990) MRI demonstration of cortical laminar necrosis and delayed white matter injury in anoxic encephalopathy. Neuroradiology 32:319-321. doi

$10.1007 /$ bf00593053

43. Khong P-L, Ng K-C, Kwong DLW, et al. (2005) Cortical laminar necrosis in childhood intracranial germ cell tumor survivors. Pediatr Blood Cancer 44:412-415. doi: 10.1002/pbc.20270

44. Niwa T, Aida N, Shishikura A, et al. (2008) Susceptibility-weighted imaging findings of cortical laminar necrosis in pediatric patients. AJNR Am J Neuroradiol 29:1795-1798. doi:

10.3174/ajnr.A1184

45. Samain JL, Haven E, Gille M, Mathys P (2011) Typical CT and MRI features of cortical laminar necrosis. JBR-BTR 94:357. doi: 10.5334/jbr-btr.713

46. Dang M, Phillips PC (2017) Pediatric Brain Tumors. Continuum (Minneap Minn) 23:1727-1757. doi: 10.1212/CON.0000000000000545

47. Prabhu VC, Brown HG (2005) The pathogenesis of craniopharyngiomas. Childs Nerv Syst 21:622-627. doi: 10.1007/s00381-005-1190-9

48. Bunin GR, Surawicz TS, Witman PA, et al. (1998) The descriptive epidemiology of craniopharyngioma. J Neurosurg 89:547-551. doi: 10.3171/ins.1998.89.4.0547

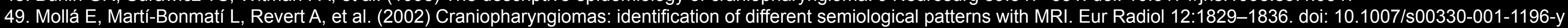

50. Zhao X, Yi X, Wang H, Zhao H (2012) An analysis of related factors of surgical results for patients with craniopharyngiomas. Clin Neurol Neurosurg 114:149-155. doi: 